\title{
sciendo
}

\section{Clozapine impact on FosB/ $\Delta$ FosB expression in stress preconditioned rats: response to a novel stressor}

\author{
Jana Osack A ${ }^{1}$, Lubica Horvathova ${ }^{1}$, Alena Cernackova ${ }^{1,2}$, Alexander Kiss ${ }^{1}$ \\ ${ }^{1}$ Institute of Experimental Endocrinology, Biomedical Research Center, Slovak Academy of Sciences, Bratislava, Slovakia; \\ ${ }^{2}$ Institute of Physiology, Faculty of Medicine, Comenius University in Bratislava, Bratislava, Slovakia \\ E-mail: jana.bundzikova@savba.sk
}

Objective. Prolonged treatment with neuroleptics has been shown to induce FosB $/ \Delta$ FosB expression in several brain regions including the medial prefrontal cortex, dorsomedial and dorsolateral striatum, ventrolateral and dorsolateral septum, nucleus accumbens shell and core, and the hypothalamic paraventricular nucleus (PVN). Some of these regions are known to be also stress responsive. This study was designed to determine whether repeated clozapine (CLZ) administration for 7 consecutive days to Wistar rats may modify FosB/ $\Delta$ FosB expression in the above-mentioned brain areas induced by acute stress or novel stressor that followed 13-day chronic mild stress preconditioning.

Methods. Following experimental groups were used: unstressed animals treated with vehicle/ CLZ for 7 days; 7-day vehicle/CLZ-treated animals on the last day exposed to acute stress - forced swimming (FSW); and animals preconditioned with stress for 13 days treated from the $8^{\text {th }}$ day with vehicle/CLZ and on the $14^{\text {th }}$ day exposed to novel stress - FSW.

Results. In the unstressed animals CLZ markedly increased FosB/ $\Delta$ FosB immunoreactivity in the ventrolateral septum and PVN. FSW elevated FosB/ $\triangle$ FosB expression in the medial prefrontal cortex, striatum, and septum. CLZ markedly potentiated the effect of the FSW on FosB/ $\Delta$ FosB expression in the PVN, but suppressed it in the dorsomedial striatum. Novel stress with stress preconditioning increased FosB $/ \Delta$ FosB immunoreactivity in the prefrontal cortex, striatum, ventrolateral septum, and the PVN. In the nucleus accumbens the effect of the novel stressor was potentiated by CLZ.

Conclusion. Our data indicate that CLZ may modulate the acute as well as novel stress effects on FosB $/ \Delta$ FosB expression but its effect differs within the individual brain regions.

Key words: clozapine, acute and novel stress, chronic mild stress, FosB $/ \Delta \mathrm{FosB}$, forebrain

Clinical effects of psychotropic drugs, including antipsychotics, are mediated not only via their interaction with various receptors, but also via regulation of gene expression. The potential mediators include transcription factors encoded by immediate early genes (IEG) (Atkins et al. 1999). The best characterized IEG are proteins of the Fos family that include c-Fos, FosB, Fra-1, and Fra-2 (Kovacs 1998). Previous studies have shown that expression of Fos family transcription factors is differently regulated by acute and chronic stimulations in the brain. It has been shown that exposure to acute stressors induces c-Fos expression mainly in the frontal cortex, nucleus accumbens (nAcc), lateral septum, thalamus, hypo-

Corresponding author: Jana Osacka, PhD., Institute of Experimental Endocrinology, Biomedical Research Center, Slovak Academy of Sciences, Dubravska cesta 9, 84505 Bratislava, Slovak Republic; phone: +421 232295 214; e-mail: jana.bundzikova@savba.sk. 
thalamic paraventricular nucleus (PVN), and the hippocampus (Melia et al. 1994; Senba et al. 1994; Senba and Ueyama 1997; Bubser and Deutch 1999; Morrow et al. 2000). In contrary, repeated exposure to stress desensitizes c-Fos response in many of these brain regions (Melia et al. 1994; Umemoto et al. 1997; Stamp and Herbert 1999) and in some of them increases FosB-like immunoreactivity (Umemoto et al. 1997; Stamp and Herbert 1999, 2001). Perrotti et al. (2004) have proven that protein responsible for this FosB-like immunoreactivity after chronic stress is in fact $\Delta$ FosB, actually $35-37 \mathrm{kD}$ isoform of FosB $/ \Delta$ FosB. Induction of FosB $/ \Delta$ FosB by chronic stress is evident in numerous brain regions but most pronounced in the frontal cortex, nAcc, basolateral nucleus of the amygdala, lateral septum, and locus coeruleus (Perrotti et al. 2004).

Acute and chronic antipsychotics treatments induce c-Fos and FosB $/ \Delta$ FosB expressions in different brain regions, too (Sebens et al. 1995). Chronic drug exposure desensitizes c-Fos response (Sebens et al. 1995; Hiroi and Graybiel 1996; Atkins et al. 1999). However, for both typical and atypical neuroleptics it may take days/weeks to achieve the maximal efficacy (Kontkanen et al. 2002). $\Delta$ FosB, unlike c-Fos and full-length FosB/ $\Delta$ FosB, accumulates along with the chronic drug exposure because of its long half-life degradation (Chen et al. 1997). Dietz et al. (2014) have detected increased $\triangle F$ FosB levels in the prefrontal cortex (PFC) of medicated schizophrenic patients, but not in the non-medicated ones. The above-mentioned authors have confirmed that augmented $\Delta$ FosB levels are the results of the prolonged drug action. $\Delta$ FosB is thought to mediate some of the longer-lasting transcriptional changes induced by antipsychotic drugs in the nAcc and dorsal striatum (Nestler et al. 2001; McClung and Nestler 2003). Increased $\Delta$ FosB expression has been found in the caudate putamen after treatment with a typical (haloperidol) and also atypical (risperidone, olanzapine, and asenapine) neuroleptics, in the nAcc after asenapine and haloperidol treatment, and in the PFC only after haloperidol application (Atkins et al. 1999; Majercikova et al. 2016). CLZ did not stimulate $\triangle$ FosB expression in any of the areas studied (Atkins et al. 1999). Hiroi and Graybiel (1996) have obtained similar data in the caudate putamen. After 8-day treatment with typical neuroleptics, the above-mentioned authors have observed augmented levels of $\Delta$ FosB, however, atypical CLZ did not increase but even downregulated the inducibility of $\triangle$ FosB in the striatum. On the other hand, Grande et al. (2004) have shown that neuroleptics may differentially induce $\Delta$ FosB in the $n A c c$ and the caudate putamen. While in the nAcc they detected increased $\triangle$ FosB after chronic haloperidol and CLZ application, in the caudate putamen, $\Delta$ FosB expression was elevated only after haloperidol treatment.

Former studies have indicated that the effect of antipsychotics in the clinical use is partly interlinked with the status of the stress responsive hypothalamopituitary-adrenal (HPA) axis (Sebens et al. 2001). Moreover, in our previous study we have shown that CLZ can modify c-Fos response to stress in some of the brain structures (Osacka et al. 2018). The aim of our current study was to determine whether 7-day CLZ administration may modify FosB/ $\Delta$ FosB expression in the selected forebrain areas (which are known to be affected by antipsychotics and also by stress) in acutely stressed animals and animals previously exposed to 13-day chronic mild stress and then to a novel stressor. We were interested to find out: 1) the effect of 7-day CLZ administration on FosB/ $\triangle F$ osB expression in the selected forebrain areas in unstressed animals; 2) whether 7-day CLZ administration may modify FosB $/ \Delta$ FosB expression in the selected forebrain areas in animals exposed to the acute stimulus - forced swimming (FSW); and 3) whether 7-day CLZ administration may modify FosB/ $\Delta$ FosB expression in the selected forebrain areas in animals 13-day preconditioned with mild unpredictable stress (CMS) and then exposed to novel stressor - FSW. The activity of cells was evaluated by FosB/ $\triangle$ FosB immunoreactivity (that reflects chronic stimulation) in the medial prefrontal cortex (mPFC), the dorsolateral (DL Str) and the dorsomedial (DM Str) striatum, the dorsolateral (dLS) and the ventrolateral (vLS) septum, the accumbens nucleus core (nAcc Core) and shell (nAcc Shell), and the PVN.

\section{Material and methods}

Animals. Forty male Wistar rats (age 7-8 weeks, weighing 200-230 $\mathrm{g}$ at the beginning of the experiment) were purchased from Charles River (Germany). Animals were housed one per cage in a room with controlled temperature $\left(22 \pm 1^{\circ} \mathrm{C}\right)$, light (12-h light/ dark cycle with lights on at 06:00 h), and humidity $(55 \% \pm 10)$. Animals were provided with a regular rat chow (dry pellets) and tap water ad libitum. Principles of the laboratory animal care and the experimental procedures used have been approved by Animal Care Committee of the Institute of Experimental Endocrinology, Biomedical Research Center, Slovak Academy of Sciences, Slovak Republic.

Experimental design. Experimental animals were randomly divided into the following groups: 
1) unstressed animals treated with vehicle for 7 days (VEH, n=4); 2) unstressed animals treated with CLZ for 7 days (CLZ, n=4); 3) 7 days VEH-treated animals and on the last day exposed to acute stressor - forced swimming (VEH+FSW, $\mathrm{n}=8$ ); 4) 7 days CLZ-treated animals on the last day exposed to acute stressor - forced swimming (CLZ+FSW, $\mathrm{n}=8)$; 5) animals 13 days preconditioned with stress, since the $8^{\text {th }}$ day treated with $\mathrm{VEH}$ and on the $14^{\text {th }}$ day exposed to novel stressor - forced swimming (CMS+VEH, $\mathrm{n}=8) ; 6$ ) animals 13 days preconditioned with stress, since the $8^{\text {th }}$ day treated with CLZ and on the $14^{\text {th }}$ day exposed to novel stressor - forced swimming (CMS+CLZ, $\mathrm{n}=8$ ).

The animals were intraperitoneally (i.p.) injected with vehicle $(0.1 \%$ acetic acid in saline $(100 \mu \mathrm{l} / 100 \mathrm{~g}$, Slavus, Slovakia) or CLZ (10 mg/kg/day; SigmaAldrich, USA) dissolved in vehicle (Kim et al. 2012) for consecutive 7 days. Stress preconditioned animals were exposed to CMS for 13 days. The stressors included: restraint stress in plastic restrainers (30-60 min), cages switch overnight, crowding overnight, cold room $\left(4{ }^{\circ} \mathrm{C} ; 40-60 \mathrm{~min}\right)$, and open field (OF, $5 \mathrm{~min}$ ). The animals received one stress challenge per day. In order to minimize the stressors predictability, the particular stressor was applied each day at different time. On the last day of the experiment, FSW was used as an acute stressor in $\mathrm{VEH}+\mathrm{FSW} / \mathrm{CLZ}+\mathrm{FSW}$ experimental groups or as a novelty stressor in CMS+VEH/CMS+CLZ experimental groups. The FSW was performed in a tank (plexiglas cylinder with a height of $45 \mathrm{~cm}$ and diameter of $20 \mathrm{~cm}$ ) filled with approximately up to $31 \mathrm{~cm}$ of water height $\left(23-25^{\circ} \mathrm{C}\right)$ for $10 \mathrm{~min}$.

Ninety minutes after the FSW and 120 min after the last CLZ injection, the animals were anesthetized with sodium pentobarbital $(50 \mathrm{mg} / \mathrm{kg}$ of b.w., i.p.; Spofa, Czech Republic), perfused with $50 \mathrm{ml}$ of cold isotonic saline (Braun, Germany) containing $450 \mu \mathrm{l}$ of heparin (5000 IU/1, Zentiva, Prague, Czech Republic), followed by $250 \mathrm{ml}$ of fixative containing $4 \%$ paraformaldehyde (Sigma-Aldrich, USA) in $0.1 \mathrm{M}$ phosphate buffer (PB, $\mathrm{pH} 7.4)$. After the fixation, the brains were removed and postfixed in a fresh fixative overnight. Then, the brains were two times washed in $0.1 \mathrm{M} \mathrm{PB}$, infiltrated with $30 \%$ sucrose for 2 days at $4{ }^{\circ} \mathrm{C}$, and cut with the cryocut (HYRAX C-50, Carl Zeiss, Germany) into $30 \mu \mathrm{m}$ thick coronal sections into 4 series.

Immunohistochemistry. Sections with the studied brain areas from the $1^{\text {st }}$ and $3^{\text {rd }}$ series were used for the following immunohistochemical reaction. Free floating sections were repeatedly washed in cold $0.1 \mathrm{M} \mathrm{PB}$ and preincubated with $0.3 \% \mathrm{H}_{2} \mathrm{O}_{2}$ (Sigma-Aldrich, USA) in $0.1 \mathrm{M} \mathrm{PB}$ for $30 \mathrm{~min}$ at room temperature (RT). Then the sections were rinsed $3 \times 10 \mathrm{~min}$ in $0.1 \mathrm{M} \mathrm{PB}$ and incubated with a mouse monoclonal anti-FosB/ $\triangle$ FosB antibody (1:500, ab11959, Abcam, Cambridge, UK) diluted in $0.1 \mathrm{M}$ $\mathrm{PB}$ containing $4 \%$ normal goat serum (Gibco, Grand Island, NY, USA), 0.5\% Triton X-100 (Sigma-Aldrich, USA), and $0.1 \%$ sodium azide (Sigma-Aldrich, USA) for $48 \mathrm{~h}$ at $4{ }^{\circ} \mathrm{C}$. After several rinsing in $0.1 \mathrm{M} \mathrm{PB}$, the sections were incubated with biotinylated goat anti-rabbit IgG (1:500, Vector Laboratories, Inc., Burlingame, CA, USA) in 0.1 M PB for $90 \mathrm{~min}$ at RT. Next $0.1 \mathrm{M}$ PB rinsing was followed by incubation with the avidin-biotin peroxidase complex (1:250, Vector Laboratories, Inc., Burlingame, CA, USA) for $90 \mathrm{~min}$ at RT. After several washings in $0.05 \mathrm{M}$ sodium acetate buffer ( $\mathrm{SAB}, \mathrm{pH} 6.0$ ), FosB/ $\Delta$ FosB antigenic sites were visualized by nickel-enhanced 3,3'-diaminobenzidine tetrahydrochloride (2.5\% nickel chloride, $0.0625 \%$ DAB, Sigma-Aldrich, USA), in SAB containing $0.0006 \%$ hydrogen peroxide until black staining of the FosB/ $\Delta$ FosB labeled nuclei was achieved. The developing process was monitored under the light microscope and the developing time ranged from 5 to $10 \mathrm{~min}$. Immunostaining reactions were conducted by an unbiased manner.

Quantification of FosB/ $\Delta$ FosB immunoreactive cells. Quantification of FosB $/ \Delta$ FosB immunoreactive cells was performed in the brain structures at the following Bregma levels: the mPFC (3.2-2.7 mm), nAcc Shell, nAcc Core (1.6-1 mm), vLS, dLS, DL Str, and DM Str (1.2-0.7 mm), and PVN (-1.08 to $-1.8 \mathrm{~mm})$ (Paxinos and Watson 1998) (Figure 1). Digital images of the selected areas were captured at $100 \times$ magni-

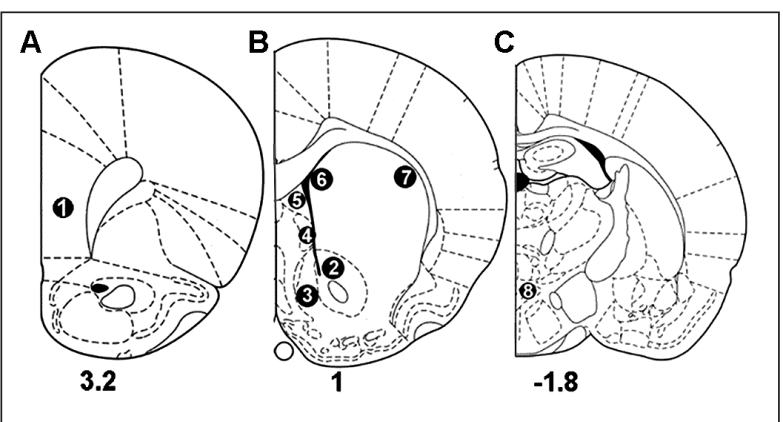

Figure 1. Localization of the brain areas selected for the counting of FosB/ $\Delta$ FosB positive cells. (A) $3.2 \mathrm{~mm}$ from Bregma; (B) $1.0 \mathrm{~mm}$ from Bregma; (C) $-1.8 \mathrm{~mm}$ from Bregma; 1 - medial prefrontal cortex; 2 - nucleus accumbens core; 3 - nucleus accumbens shell; 4 - ventrolateral septum; 5 - dorsolateral septum; 6 - dorsomedial striatum; 7 - dorsolateral striatum; 8 hypothalamic paraventricular nucleus. 
fication with Axio Scope.A1, and AxioCam ERc 5s camera (Carl Zeiss, Germany). FosB/ $\Delta$ FosB positive neurons were counted manually in CellCounterl.2. (at least 4 sections/structure/animal). Counting of FosB $/ \Delta$ FosB immunopositive cells was performed by a person blind to treatment and conditions. Number of $\mathrm{FosB} / \Delta \mathrm{FosB}$ immunopositive cells is expressed unilaterally.

Statistical analysis. FosB $/ \triangle$ FosB analysis was performed by two-way ANOVA for factors treatment (VEH and CLZ) and conditions (stress exposure) followed by Tukey post hoc test. The results are reported as mean \pm S.E.M. Differences were considered significant at $p<0.05$. The outliers were excluded if the data point more than 1.5 interquartile ranged below the first quartile or above the third quartile.

\section{Results}

In the mPFC, two-way ANOVA revealed influence of the stress on FosB $/ \Delta$ FosB expression $(\mathrm{F}(2,35)=10.565, \mathrm{p}<0.001) . \quad$ In the VEH-treated animals, exposure to FSW, as an acute stressor and also as a novel stressor, increased the number of
FosB/AFosB immunopositive cells in comparison with the unstressed animals ( $\mathrm{p}=0.002$, resp. $\mathrm{p}=0.005$; Figure 2).

In the DL Str, two-way ANOVA confirmed the effect of the stress exposure $(F(2,37)=10.483, p<0.001)$ on FosB/ $\mathrm{F}$ FosB immunoreactivity. VEH-injected animals that underwent a single FSW and FSW with previous CMS exhibited more FosB/ $\Delta$ FosB immunoreactive cells than the VEH unstressed ones $(p=0.001$, resp. $\mathrm{p}=0.004$; Figure $3 \mathrm{~A}$ ). Also, $\mathrm{CMS}+\mathrm{CLZ}$ animals exhibited more FosB/ $\Delta$ FosB-immunoreactive profiles in comparison with the CLZ unstressed ones $(\mathrm{p}=0.044$; Figure $3 \mathrm{~A})$.

In the DM Str, the effect of the treatment $(\mathrm{F}(2,33)=17.199, \mathrm{p}<0.001)$ and interaction of the treatment and stress exposure $(F(2,33)=3.691, p=0.038)$ on FosB $/ \triangle$ FosB immunoreactivity was found by two-way ANOVA. VEH+FSW and CMS+VEH experimental groups showed markedly stronger FosB/ $\triangle$ FosB expression than the unstressed VEH-injected one ( $<<0.001$, resp. $p=0.008$; Figure $3 \mathrm{~B})$. The animals that underwent single FSW (VEH+FSW) had significantly more FosB/ $\Delta$ FosB immunopositive cells than the stress preconditioned ones (CMS+VEH, $\mathrm{p}=0.044$;

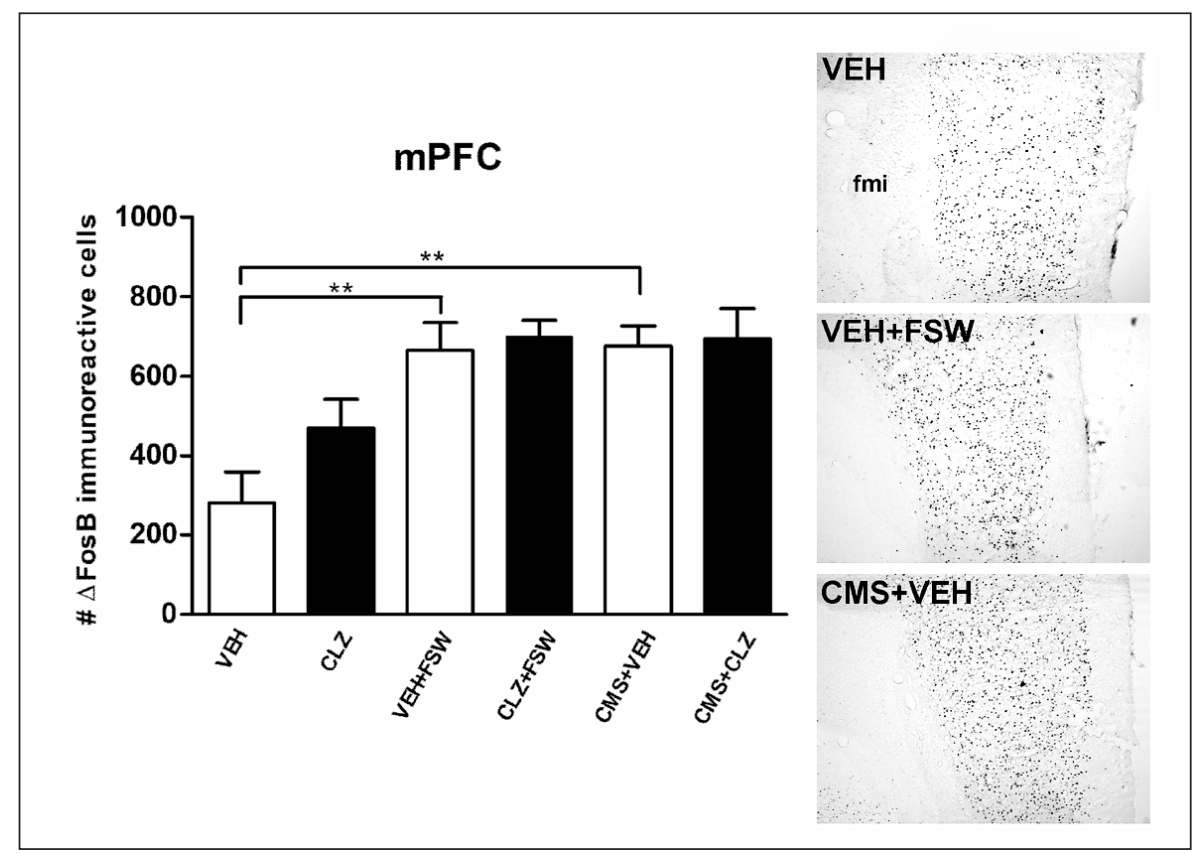

Figure 2. Graph demonstrating the effect of the stress exposure and CLZ treatment on FosB/ $\triangle$ FosB expression in the mPFC. VEHtreated animals exposed to FSW and also those exposed to previous CMS had more FosB/ $\triangle$ FosB immunoreactive cells than the unstressed ones $\left({ }^{* *} \mathrm{p}<0.01\right)$. Data are expressed as mean \pm SEM. Photomicrographs illustrate the stimulatory effect of acute FSW and CMS followed by novelty on FosB/ $\triangle$ FosB expression in the mPFC. Abbreviations: CMS+CLZ - stress preconditioned animals exposed to a novelty stressor - forced swimming, treated with CLZ; CMS+VEH - stress preconditioned animals exposed to a novelty stressor - forced swimming, treated with VEH; CLZ - clozapine; CLZ+FSW - animals exposed to acute stressor - forced swimming, treated with CLZ; fmi - forceps minor corpus callosum; mPFC - medial prefrontal cortex; VEH - vehiculum; VEH+FSW - animals exposed to acute stressor - forced swimming, treated with VEH. 


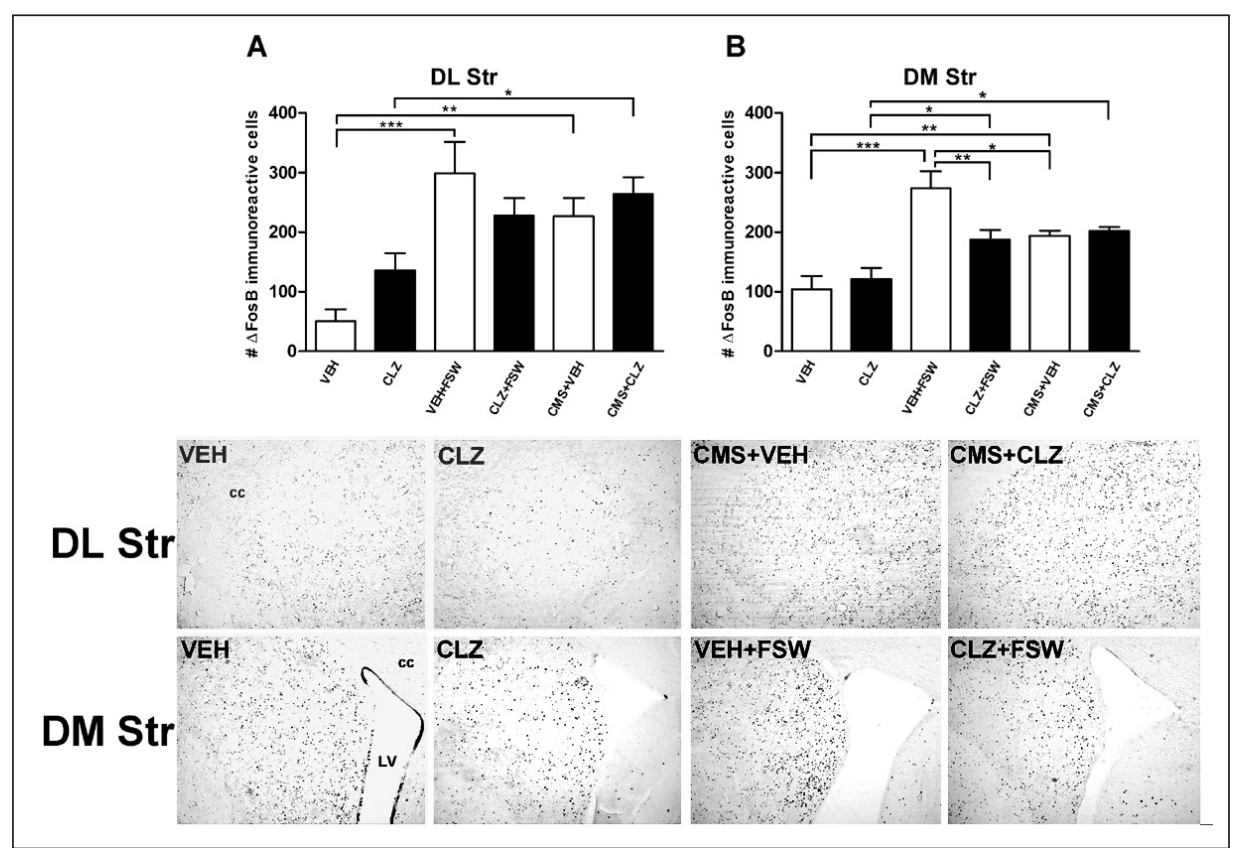

Figure 3. Graphs demonstrating the effect of the stress exposure and CLZ treatment on FosB/ $\triangle$ FosB expression in the DL Str (A) and DM Str (B). (A) In the VEH-treated animals, both stressed groups had higher number of FosB/ $\Delta$ FosB immunoreactive cells than the unstressed one. In the CLZ-injected rats, CMS exposure increased FosB/ $\Delta \mathrm{FosB}$ immunoreactivity in comparison with the unstressed ones. (B) In the DM Str, both stressed VEH and also CLZ-treated experimental groups had more FosB/ $\Delta$ FosBimmunoreactive cells than the unstressed ones. Vehicle-injected stress preconditioned animals had less FosB/ $\Delta$ FosB immunopositive cells in comparison with the acute FSW exposed ones. CLZ suppressed FosB/ $\triangle$ FosB immunoreactivity in the single FSWexposed animals. ( $\left.{ }^{*} \mathrm{p}<0.05,{ }^{* *} \mathrm{p}<0.01,{ }^{* * *} \mathrm{p}<0.001\right)$. Data are expressed as mean $\pm \mathrm{SEM}$. Photomicrographs illustrate the effect of 7 -day CLZ administration and FSW exposure as acute or novel stressor on FosB/ $\Delta$ FosB expression in the DL Str and DM Str. Abbreviations: cc - corpus callosum; CMS+CLZ - stress preconditioned animals exposed to a novelty stressor - forced swimming, treated with CLZ; CMS+VEH - stress preconditioned animals exposed to a novelty stressor - forced swimming, treated with VEH; CLZ - clozapine, CLZ+FSW - animals exposed to acute stressor - forced swimming, treated with CLZ; DL Str - dorsolateral striatum; DM Str - dorsomedial striatum; LV - lateral ventricle; VEH - vehiculum; VEH+FSW - animals exposed to acute stressor - forced swimming, treated with VEH.

Figure 3B). In the CLZ-treated animals, FosB/AFosB expression was elevated in the rats exposed to a single FSW and also in those exposed to a previous CMS when compared with the unstressed CLZ-injected ones ( $p=0.045$, resp. $p=0.018$; Figure 3B). Notably, in the single FSW exposed rats, CLZ markedly suppressed FosB $/ \triangle$ FosB immunoreactivity $(\mathrm{p}=0.006$; Figure 3B).

In thevLS, the effect of the treatment $(\mathrm{F}(1,35)=19.974$, $\mathrm{p}<0.001)$, stress exposure $(\mathrm{F}(2,35)=3.655, \mathrm{p}=0.038)$, and their interaction $(\mathrm{F}(2,35)=6.898, \mathrm{p}=0.003)$ on $\mathrm{FosB} / \Delta \mathrm{FosB}$ expression was found by two-way ANOVA. In the unstressed animals CLZ markedly stimulated FosB $/ \Delta$ FosB immunoreactivity $(\mathrm{p}<0.001$, Figure 4A). VEH-injected animals that underwent single FSW and FSW with previous CMS exhibited more $\triangle \mathrm{FosB}$ immunoreactive cells than the $\mathrm{VEH}$ unstressed ones $(p<0.001, p=0.002$; Figure $4 A)$.

In the dLS, two-way ANOVA confirmed the effect of the stress exposure $(\mathrm{F}(2,35)=4.535, \mathrm{p}=0.019)$ on FosB/ $\Delta$ FosB immunoreactivity. In the VEHtreated animals, exposure to a single FSW induced stronger FosB $/ \Delta$ FosB expression in comparison with unstressed VEH-treated rats ( $\mathrm{p}=0.01$; Figure 4B).

In the nAcc Core, two-way ANOVA found impact of the stress exposure $(F(2,32)=5.781, p=0.008)$ on the number of FosB $/ \Delta$ FosB immunopositive cells. In the CMS+CLZ group, more FosB/ $\triangle$ FosB immunoreactive cells appeared than in the CMS+VEH $(\mathrm{p}=0.022)$ and CLZ+FSW $(\mathrm{p}=0.009)$ experimental groups (Figure 5A).

In the nAcc Shell, two-way ANOVA detected effect of the interaction of the treatment and stress exposure $(\mathrm{F}(2,33)=3.623, \mathrm{p}=0.04)$ on $\mathrm{FosB} / \Delta \mathrm{FosB}$ immunoreactivity. CMS+CLZ animals expressed significantly more FosB $/ \triangle$ FosB immunopositive cells than the CMS+VEH $(\mathrm{p}=0.019)$ and CLZ+FSW $(\mathrm{p}=0.023)$ ones (Figure. 5B).

In the PVN, effect of the treatment $(\mathrm{F}(1,34)=26.987$, $\mathrm{p}<0.001)$ and interaction of the treatment and stress 


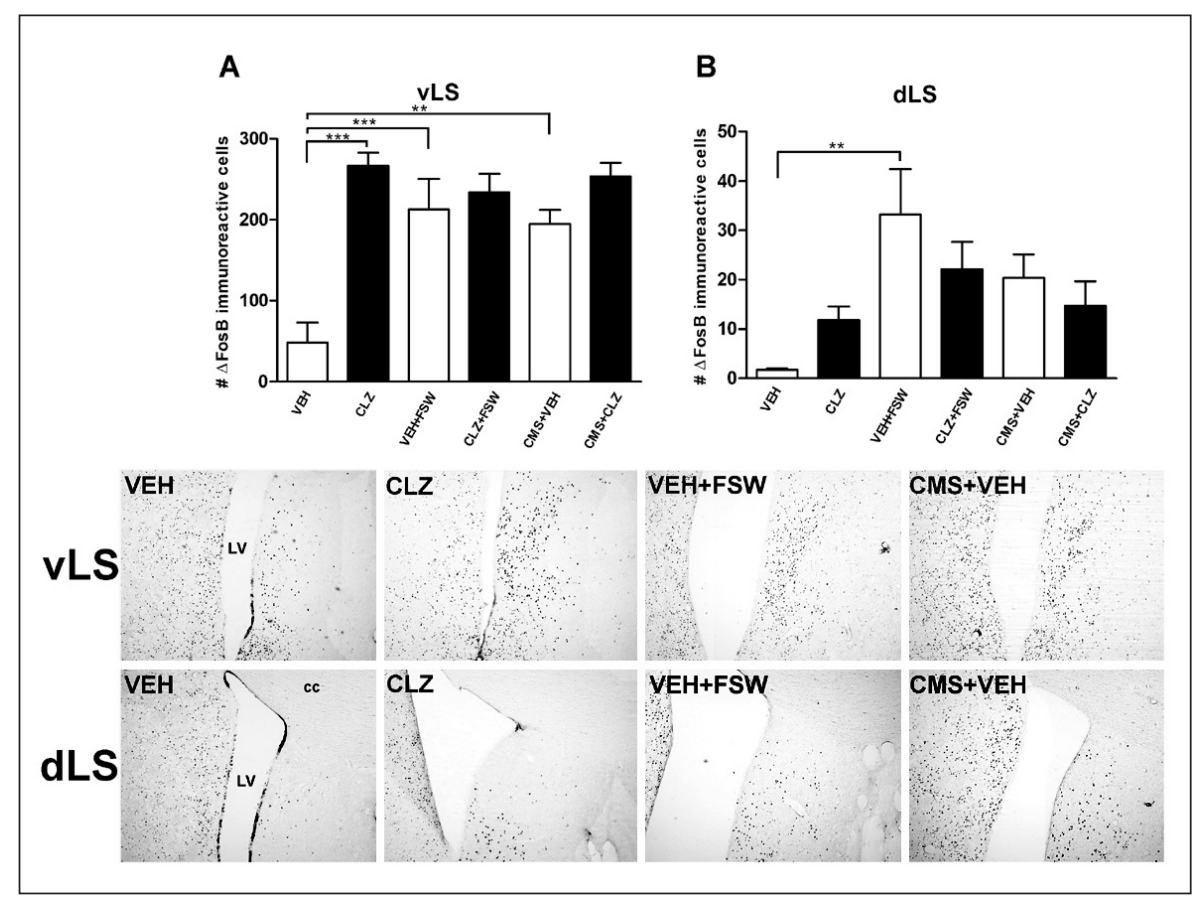

Figure 4. Graphs demonstrating the effect of the stress exposure and CLZ treatment on FosB/ $\triangle$ FosB expression in the vLS (A) and dLS (B). (A) Note that in the vLS, both stressed VEH-treated groups had higher number of FosB/ $\triangle$ FosB immunoreactive cells than the unstressed VEH-treated animals. CLZ increased FosB/ $\triangle$ FosB immunoreactivity only in the unstressed animals. (B) In the dLS, only single FSW exposed VEH-injected experimental group had stronger FosB/ $\Delta$ FosB immunoreactivity than the unstressed one. $\left({ }^{*} \mathrm{p}<0.05,{ }^{* * *} \mathrm{p}<0.01,{ }^{* * *} \mathrm{p}<0.001\right)$. Data are expressed as mean \pm SEM. Photomicrographs illustrate the effect of 7 -day CLZ administration, FSW, and CMS exposure on FosB/ $\triangle$ FosB expression in the dLS and vLS. Abbreviations: cc - corpus callosum; CMS+CLZ - stress preconditioned animals exposed to a novelty stressor - forced swimming, treated with VEH; CMS+VEH - stress preconditioned animals exposed to a novelty stressor - forced swimming, treated with VEH; CLZ - clozapine; CLZ+FSW - animals exposed to acute stressor - forced swimming, treated with CLZ; dLS - dorsolateral septum; LV - lateral ventricle; vLS - ventrolateral septum; VEH - vehiculum; VEH+FSW - animals exposed to acute stressor - forced swimming, treated with VEH.

exposure $(\mathrm{F}(2,34)=5.572, \mathrm{p}=0.009)$ on $\mathrm{FosB} / \Delta \mathrm{FosB}$ expression were detected by two-way ANOVA. $\mathrm{CMS}+\mathrm{VEH}$ experimental group had more FosB/ $\triangle$ FosB immunoreactive cells than the unstressed VEH group ( $p=0.004$; Figure 6$)$. In the unstressed animals and those exposed to single FSW, CLZ markedly stimulated FosB/ $\Delta$ FosB expression in comparison with the VEH-treated groups (VEH vs. CLZ $\mathrm{p}<0.001 ; \mathrm{VEH}+\mathrm{FSW}$ vs. CLZ+FSW $\mathrm{p}=0.005$; Figure 6).

\section{Discussion}

The present study suggests that 7-day CLZ administration increases FosB $/ \Delta$ FosB expression in the selected forebrain areas in unstressed animals (PVN, vLS) and may interact either with acute or chronic stress and consequently affect the FosB/ $\Delta$ FosB expression.

Our previous study, concerning c-Fos expression (as a marker of an acute stimulation), have shown that CLZ may modify c-Fos immunoreactivity in the unstressed, acutely, and repeatedly stressed animals in some of the forebrain areas (Osacka et al. 2018). When we compared the data from our previous study, i.e. number of cells expressing c-Fos, and the data obtained in this study, i.e. number of cells expressing FosB/ $\Delta$ FosB within the same areas, we found that the cells in the dorsal striatum and nAcc of unstressed, acutely, and chronically stressed rats expressed approximately 10 times more FosB/ $\Delta$ FosB immunoreactive profiles than c-Fos. In these structures, 7-day CLZ treatment and acute/chronic stress seem to affect FosB/ $\Delta$ FosB expression (a marker of prolonged stimulus) more intensively than in the other areas studied.

Robust FosB/ $\Delta$ FosB expression, especially after treatment with typical antipsychotics like haloperidol, has been observed in the caudate putamen and the nucleus accumbens, and a small increase also in the prefrontal cortex (Atkins et al. 1999). Pattern of FosB $/ \Delta$ FosB induction seems to be associated with 
the extrapyramidal side effects generated by typical antipsychotics (Atkins et al. 1999). Majercikova et al. (2016) have found elevated FosB/AFosB in the striatum and the nucleus accumbens also after treatment with an atypical drug, asenapine. In the most of the studies, CLZ failed to increase FosB/ $\Delta$ FosB in all of the above-mentioned areas (Hiroi and Graybiel 1996; Atkins et al. 1999). However, Vahid-Ansari et al. (1996) and Robertson et al. (2004) have detected elevated FosB/ $\triangle$ FosB immunoreactivity after CLZ application in the caudate putamen, nAcc, PFC, lateral septal nucleus, and the island of Calleja. In the present study, we found elevated FosB/ $\Delta$ FosB immunoreactivity in the vLS and the PVN.

Acute and chronic stressors increased FosB $/ \Delta$ FosB expression in the most of the areas studied (mPFC, PVN, striatum, septum). One of the previous studies has shown a robust $\triangle$ FosB mRNA upregulation in the striatum after acute treatment with amphetamine and very similar pattern of $\triangle$ FosB mRNA induction after restraint stress. This induction was partially reduced by repeated amphetamine/stress exposures (Alibhai et al. 2007). We also detected decreased FosB $/ \Delta$ FosB immunoreactivity in the
DM Str of chronically stressed animals exposed to a novel FSW episode when compared with the acutely stressed ones. Notably, in the PVN of chronically stressed animals exposed to a novel stressor, we found a marked FosB/ $\triangle$ FosB immunoreactivity elevation (especially in its parvocellular part), but this elevation was not present after an acute FSW. These data are in contrast with the finding of Perrotti et al. (2004), who have detected a robust induction of FosB after acute stress, but no accumulation of FosB $/ \Delta$ FosB after the chronic stress. On the other hand, Kiss and Majercikova (2017) have also found increased number of FosB $/ \Delta$ FosB profiles in the medial parvocellular subdivision of the PVN in chronically stressed rats.

Our previous study has demonstrated that the reactivity of the structures involved in the stress regulation can be influenced by CLZ treatment (Osacka et al. 2018). CLZ suppressed c-Fos expression (marker of acute stimulation) in the vLS, DM Str, and nAcc after exposure to acute FSW and in the PVN after a novel stressor (Osacka et al. 2018). Present data showed that FosB/ $\Delta$ FosB expression induced by acute FSW was suppressed by CLZ in the

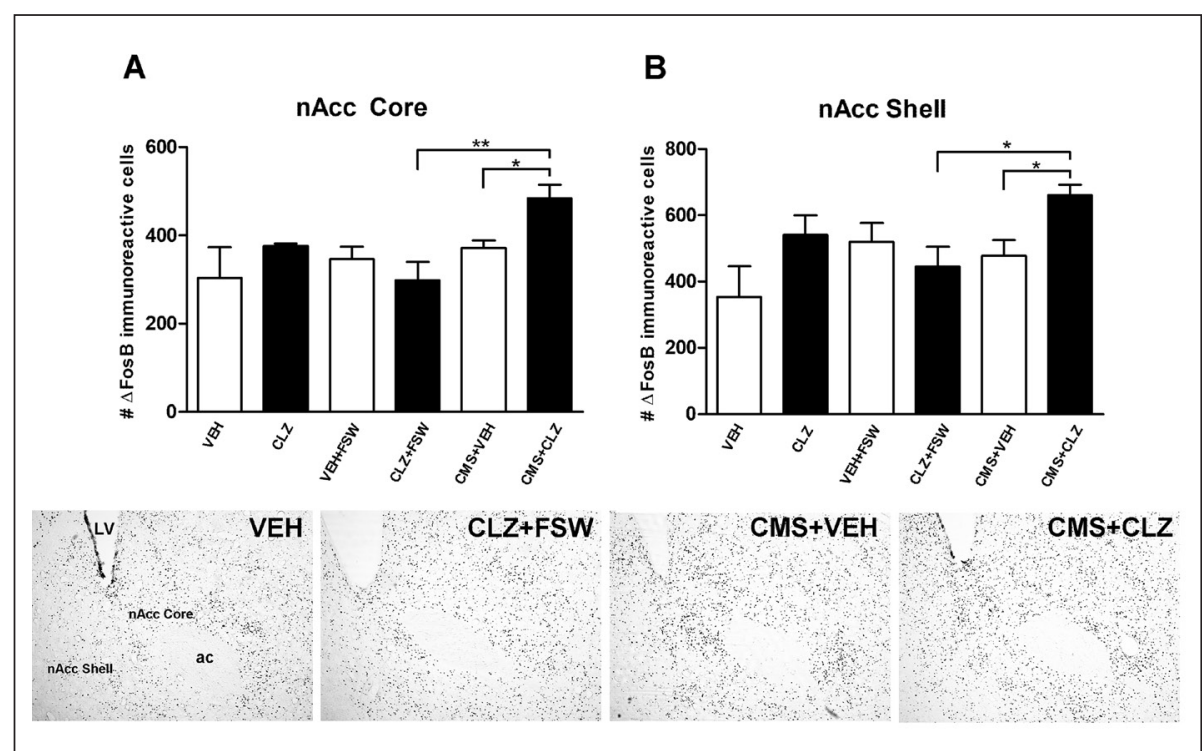

Figure 5. Graphs demonstrating the effect of the stress exposure and CLZ treatment on FosB/ $\triangle$ FosB expression in the $n A c c$ Core (A) and nAcc Shell (B). In the nAcc Core and Shell of the CMS exposed rats, CLZ significantly increased number of FosB/ $\Delta$ FosB immunoposive cells compared with the VEH-treated ones and CMS+CLZ experimental group had more FosB/ $\Delta$ FosB immunoreactive cells than the CLZ+FSW one $\left({ }^{*} \mathrm{p}<0.05,{ }^{* *} \mathrm{p}<0.01,{ }^{* * *} \mathrm{p}<0.001\right)$. Data are expressed as mean \pm SEM. Photomicrographs illustrate the effect of 7-day CLZ administration, FSW, and CMS exposure on FosB/ $\triangle$ FosB expression in the nAcc Core and nAcc Shell. Abbreviations: ac - anterior commissure; CMS+CLZ - stress preconditioned animals exposed to a novelty stressor - forced swimming, treated with CLZ; CMS+VEH - stress preconditioned animals exposed to a novelty stressor - forced swimming, treated with VEH; CLZ - clozapine; CLZ+FSW - animals exposed to acute stressor - forced swimming, treated with CLZ; LV - lateral ventricle; nAcc core - nucleus accumbens core; nAcc shell - nucleus accumbens shell; VEH - vehiculum, VEH+FSW - animals exposed to acute stressor - forced swimming, treated with VEH. 


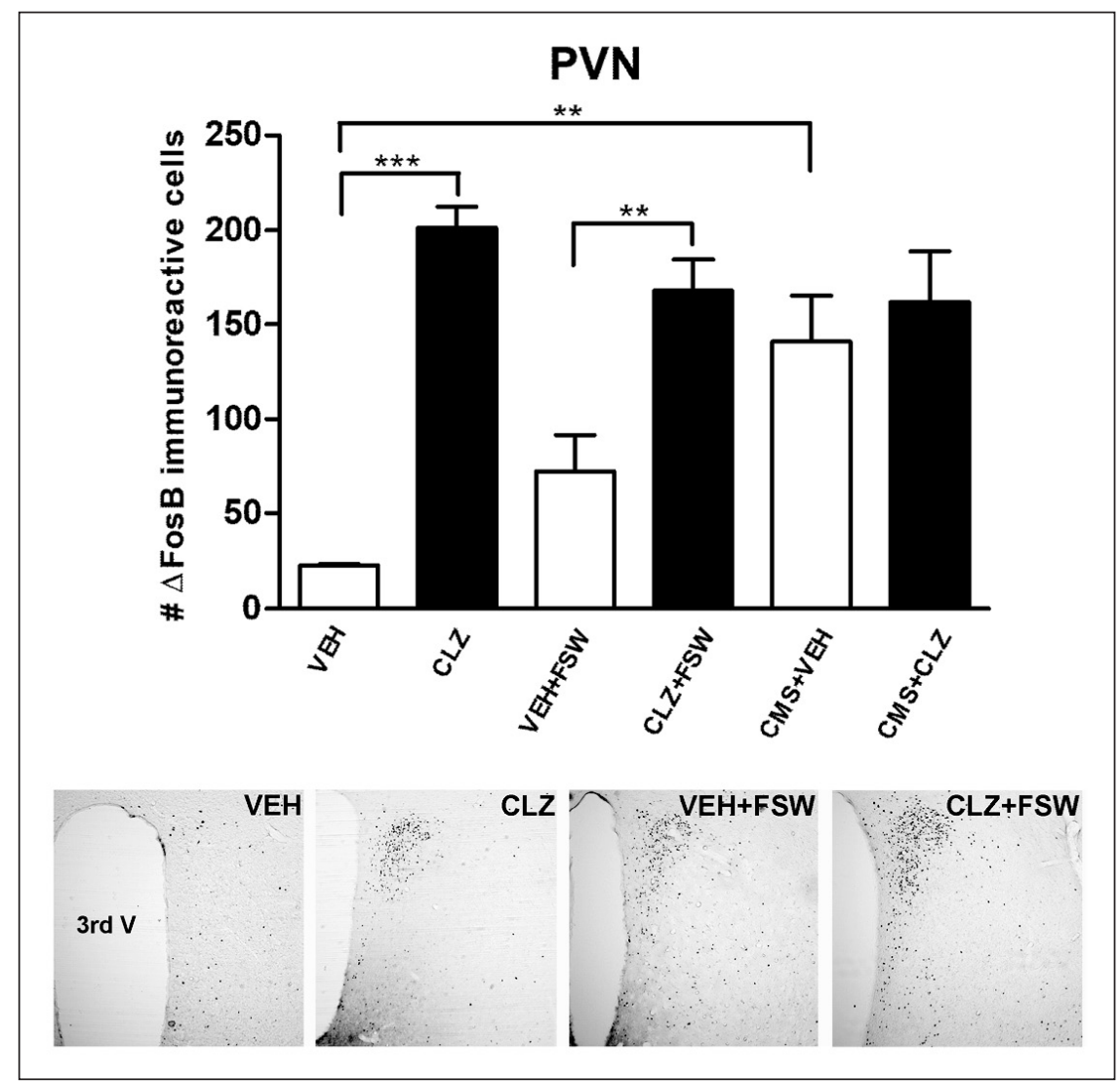

Figure 6. Graph demonstrating the effect of the stress exposure and CLZ treatment on FosB/ $\triangle$ FosB expression in the PVN. In the $\mathrm{PVN}$ of the VEH-injected animals, CMS exposure significantly increased the number of FosB/ $\Delta$ FosB cells in comparison with the unstressed animals. CLZ markedly elevated FosB/ $\triangle$ FosB expression in the unstressed animals and single FSW-exposed animals $\left({ }^{*} \mathrm{p}<0.05,{ }^{* *} \mathrm{p}<0.01\right)$. Data are expressed as mean \pm SEM. Photomicrographs illustrate the effect of 7 -day CLZ administration, FSW, and CMS exposure on FosB/ $\triangle$ FosB expression in the PVN. Abbreviations: 3rd V - 3rd ventricle; CMS+VEH - stress preconditioned animals exposed to a novelty stressor - forced swimming, treated with vehiculum; CMS+CLZ - stress preconditioned animals exposed to a novelty stressor - forced swimming, treated with clozapine; CLZ - clozapine; CLZ+FSW - animals exposed to acute stressor - forced swimming, treated with CLZ; PVN - hypothalamic paraventricular nucleus; VEH - vehiculum; VEH+FSW - animals exposed to acute stressor - forced swimming, treated with VEH.

DM Str and a similar tendency was observed also in the DL Str (but the effect did not reach statistical significance). In the striatum (especially DM Str), acute stress (FSW) seems to potentiate the effect of CLZ (as number of FosB/AFosB immunopositive cells was higher than in the unstressed CLZ-treated animals); however, CMS did not further stimulate it. In the PVN, CLZ seems to have highly stimulatory effect what we observed in the unstressed and acutely stressed animals, where CLZ-treated animals expressed significantly more FosB/ $\Delta$ FosB immunopositive cells than the VEH-treated ones (Figure 5). However, CLZ seems to be able to stimulate only certain number of cells that cannot be further potentiated by acute or chronic stress. After a novel stress, we observed the effect of CLZ in the nAcc subre- gions only, where CLZ markedly increased FosB/ $\Delta$ FosB immunoreactivity. It seems that the novel stress after CMS encourages the CLZ effect on FosB/ $\triangle$ FosB expression (it was markedly higher than in the acutely stressed animals).

$\Delta \mathrm{FosB}$ is a transcription factor, which exerts its effect by enhancing or repressing the expression of other genes. In the nAcc, $\Delta$ FosB overexpression has been shown to induce GluR2 (AMPA glutamate receptor subunit) (Kelz et al. 1999) and suppress dynorphin expression (Zachariou et al. 2006); in the nAcc in drug abuse models, $\triangle \mathrm{FosB}$ affects also Camk2a expression (Robison et al. 2014). In the PFC, increased $\triangle F o s B$ expression has been shown to be associated with social defeat-induced anxiety and depression like behavior and it has also been proven 
to enhance stress susceptibility through induction of cholecystokinin-B receptor (Vialou et al. 2014). $\Delta$ FosB targets numerous genes and further experiments are necessary to find out, which genes and consequent pathways may be affected by $\Delta$ FosB clozapine and stress inductions. However, this study showed that CLZ and stress can affect one another and modify FosB/ $\Delta$ FosB immunoreactivity in some of the forebrain areas. And the dorsal striatum and $\mathrm{nAcc}$ seem to be areas where 7-day CLZ application and stress exposure exert their most pronounced effects.

\section{Acknowledgement}

This work was supported by the grant of the Slovak Research and Development Agency (APVV-15-0037) and VEGA grant (2/0037/19) of the Slovak Academy of Sciences.

\section{References}

Alibhai IN, Green TA, Potashkin JA, Nestler EJ. Regulation of fosB and DeltafosB mRna expression: in vivo and in vitro studies. Brain Res 1143, 22-33, 2007.

Atkins JB, Chlan-Fourney J, Nye HE, Hiroi N, Carlezon WA Jr, Nestler EJ. Region-specific induction of deltaFosB by repeated administration of typical versus atypical antipsychotic drugs. Synapse 33, 118-128, 1999.

Bubser M, Deutch AY. Stress induces Fos expression in neurons of the thalamic paraventricular nucleus that innervate limbic forebrain sites. Synapse 32, 13-22, 1999.

Chen J, Kelz MB, Hope BT, Nakabeppu Y, Nestler EJ. Chronic Fos-related antigens: stable variants of deltaFosB induced in brain by chronic treatments. J Neurosci 17, 4933-4941, 1997.

Dietz DM, Kennedy PJ, Sun H, Maze I, Gancarz AM, Vialou V, Koo JW, Mouzon E, Ghose S, Tamminga CA, Nestler EJ. $\triangle$ FosB induction in prefrontal cortex by antipsychotic drugs is associated with negative behavioral outcomes. Neuropsychopharmacology 39, 538-544, 2014.

Grande C, Zhu H, Martin AB, Lee M, Ortiz O, Hiroi N, Moratalla R. Chronic treatment with atypical neuroleptics induces striosomal FosB/DeltaFosB expression in rats. Biol Psychiatry 55, 457-463, 2004.

Hiroi N, Graybiel AM. Atypical and typical neuroleptic treatments induce distinct programs of transcription factor expression in the striatum. J Comp Neurol 374, 70-83, 1996.

Kelz MB, Chen J, Carlezon WA Jr, Whisler K, Gilden L, Beckmann AM, Steffen C, Zhang YJ, Marotti L, Self DW, Tkatch T, Baranauskas G, Surmeier DJ, Neve RL, Duman RS, Picciotto MR, Nestler EJ. Expression of the transcription factor deltaFosB in the brain controls sensitivity to cocaine. Nature 401, 272-276, 1999.

Kim HW, Cheon Y, Modi HR, Rapoport SI, Rao JS. Effects of chronic clozapine administration on markers of arachidonic acid cascade and synaptic integrity in rat brain. Psychopharmacology (Berl) 222, 663-674, 2012.

Kiss A, Majercikova Z. Repeated asenapine treatment does not participate in the mild stress induced FosB/ $\Delta$ FosB expression in the rat hypothalamic paraventricular nucleus neurons. Neuropeptides 61, 57-65, 2017.

Kontkanen O, Lakso M, Wong G, Castren E. Chronic antipsychotic drug treatment induces long-lasting expression of fos and jun family genes and activator protein 1 complex in the rat prefrontal cortex. Neuropsychopharmacology 27, 152-162, 2002.

Kovacs KJ. c-Fos as a transcription factor: a stressful (re)view from a functional map. Neurochem Int 33, 287-297, 1998.

Majercikova Z, Horvathova L, Osacka J, Pecenak J, Kiss A. Impact of repeated asenapine treatment on FosB/ $\Delta$ FosB expression in the forebrain structures under normal conditions and mild stress preconditioning in the rat. Brain Res Bull 127, 29-37, 2016.

McClung CA, Nestler EJ. Regulation of gene expression and cocaine reward by CREB and DeltaFosB. Nat Neurosci 6, 1208-1215, 2003.

Melia KR, Ryabinin AE, Schroeder R, Bloom FE, Wilson MC. Induction and habituation of immediate early gene expression in rat brain by acute and repeated restraint stress. J Neurosci 14, 5929-5938, 1994.

Morrow BA, Elsworth JD, Lee EJ, Roth RH. Divergent effects of putative anxiolytics on stress-induced fos expression in the mesoprefrontal system of the rat. Synapse 36, 143-154, 2000.

Nestler EJ, Barrot M, Self DW. DeltaFosB: a sustained molecular switch for addiction. Proc Natl Acad Sci U S A 98, 11042-11046, 2001.

Osacka J, Szelle Cernackova A, Horvathova L, Majercikova Z, Pirnik Z, Kiss A. Clozapine impact on c-Fos expression in mild stress preconditioned male rats exposed to a novelty stressor. J Neurosci Res 96, 1786-1797, 2018.

Paxinos G., Watson C. The rat brain in stereotaxic coordinates. 4th edition. Academic Press, New York, USA, 1998. 
Perrotti LI, Hadeishi Y, Ulery PG, Barrot M, Monteggia L, Duman RS, Nestler EJ. Induction of deltaFosB in rewardrelated brain structures after chronic stress. J Neurosci 24, 10594-10602, 2004.

Robertson GS, Lee CJ, Sridhar K, Nakabeppu Y, Cheng M, Wang YM, Caron MG. Clozapine-, but not haloperidol-, induced increases in deltaFosB-like immunoreactivity are completely blocked in the striatum of mice lacking D3 dopamine receptors. Eur J Neurosci 20, 3189-3194, 2004.

Robison AJ, Vialou V, Sun HS, Labonte B, Golden SA, Dias C, Turecki G, Tamminga C, Russo S, Mazei-Robison M, Nestler EJ. Fluoxetine epigenetically alters the CaMKIIa promoter in nucleus accumbens to regulate $\Delta$ FosB binding and antidepressant effects. Neuropsychopharmacology 39, 1178-1186, 2014.

Sebens JB, Koch T, Ter Horst GJ, Korf J. Differential Fos-protein induction in rat forebrain regions after acute and long-term haloperidol and clozapine treatment. Eur J Pharmacol 273, 175-182, 1995.

Sebens JB, Middelveld RJ, Koch T, Ter Horst GJ, Korf J. Clozapine-induced Fos-protein expression in rat forebrain regions: differential effects of adrenalectomy and corticosterone supplement. Eur J Pharmacol 417, 149-155, 2001.

Senba E, Umemoto S, Kawai Y, Noguchi K. Differential expression of fos family and jun family mRNAs in the rat hypothalamo-pituitary-adrenal axis after immobilization stress. Brain Res Mol Brain Res 24, 283-294, 1994.

Senba E, Ueyama T. Stress-induced expression of immediate early genes in the brain and peripheral organs of the rat. Neurosci Res 29, 183-207, 1997.

Stamp JA, Herbert J. Multiple immediate-early gene expression during physiological and endocrine adaptation to repeated stress. Neuroscience 94, 1313-1322, 1999.

Stamp J, Herbert J. Corticosterone modulates autonomic responses and adaptation of central immediate-early gene expression to repeated restraint stress. Neuroscience 107, 465-479, 2001.

Umemoto S, Kawai Y, Ueyama T, Senba E. Chronic glucocorticoid administration as well as repeated stress affects the subsequent acute immobilization stress-induced expression of immediate early genes but not that of NGFIA. Neuroscience 80, 763-773, 1997.

Vahid-Ansari F, Nakabeppu Y, Robertson GS. Contrasting effects of chronic clozapine, Seroquel(TM) (ICI 204,636) and haloperidol administration of deltaFosB-like immunoreactivity in the rodent forebrain. Eur J Neurosci 8, 927-936, 1996.

Vialou V, Bagot RC, Cahill ME, Ferguson D, Robison AJ, Dietz DM, Fallon B, Mazei-Robison M, Ku SM, Harrigan E, Winstanley CA, Joshi T, Feng J, Berton O, Nestler EJ. Prefrontal cortical circuit for depression- and anxietyrelated behaviors mediated by cholecystokinin: role of $\Delta$ FosB. J Neurosci 34, 3878-3887, 2014.

Zachariou V, Bolanos CA, Selley DE, Theobald D, Cassidy MP, Kelz MB, Shaw-Lutchman T, Berton O, Sim-Selley LJ, Dileone RJ, Kumar A, Nestler EJ. An essential role for DeltaFosB in the nucleus accumbens in morphine action. Nat Neurosci 9, 205-211, 2006. 